\title{
Direito Sanitário: Autonomia e PrincípIos
}

\author{
HEALTH LAW: AUTONOMY AND PRINCIPLES
}

Alexandre Nemer Elias ${ }^{(*)}$

\section{RESUMO}

O direito à saúde vem sendo objeto de grandes debates jurídicos tanto no judiciário quanto na sociedade. No entanto, não há ainda um detalhamento científico claro sobre seus contornos e, até mesmo, quanto ao seu reconhecimento como um ramo autônomo da Ciência Jurídica. A importância do estudo para buscar tais respostas nasce da influência que este direito tem tido em todo o mundo. Considerando a amplitude dos direitos do homem, o Direito Sanitário vem se constituindo formalmente no século XX, para ser um dos mais importantes ramos do Direito no século XXI.

\section{Palavras-chave}

Autonomia do Direito; Conceito do Direito Sanitário; Princípios do Direito Sanitário.

\section{ABSTRACT}

Health Law has being discussed by the Judiciary and by society. However there is no scientific description of its details and, even though it is not recognized as an independent branch of the Legal Science. The importance of discussing such questions is based on the worldwide influence of this right. Considering the amplitude of humans right, Health Law has been formally constituted in the $20^{\text {th }}$ century to be one of the most important legal branches of the $21^{\text {th }}$ Century.

(*) Advogado, professor de Direito Sanitário pela Pontifícia Universidade Católica de Campinas (PUC-Campinas); mestrando em Direito Sanitário pela Faculdade de Saúde Pública da Universidade de São Paulo (FSP-USP); especialista em Direito Processual Civil pela PUC-Campinas. E-mail: $<$ nemer@ndadvogados.com.br>. Recebido em 18.12.06. Aprovado em 20.4.07. 


\section{Keywords}

Health Law Concept; Law Autonomy; Principles of Health Law.

\section{Introdução}

Nestas últimas décadas, observamos a concretização científica de um direito, reconhecido mundialmente há algum tempo, que implementou na Constituição da República um Sistema Constitucional de Saúde Brasileiro. Apesar dos debates intensos, este Sistema está sendo muito pouco estudado enquanto ramo autônomo da Ciência Jurídica ficando nós, cientistas, em débito com o reconhecimento da sua autonomia e do desenvolvimento de seus princípios específicos. Como afirma Ettore Jorio:

La frenetica evoluzione della legislazione della Salute, registrata nell'ultimo trentennio, sollecita la riproposizione del riconoscimento formale del diritto sanitario, quale materia autonoma, sottratta alla sua storica catalogazione di ramo particolare del diritto amministrativo. ${ }^{(1)}$

Reconhecemos que alguns juristas sanitaristas afirmam que o Direito Sanitário é um ramo autônomo da Ciência Jurídica (2); o mesmo ocorre com autores de outras áreas que abordaram o tema ${ }^{(3)}$. Porém, não houve um aprofundamento científico no assunto, pois, não temos, principalmente, um estudo detalhado dos princípios constitucionais que norteiam o Direito Sanitário.

Fazendo uma pesquisa histórica, verificamos que a primeira obra jurídica a tratar do Direito Sanitário surgiu em Milão, na Itália, de autoria de Silvio Lessona. O autor italiano escreveu, pela primeira vez, um "Trattato di diritto sanitario", em 1914, no qual conceitua este Direito e discorre sobre o sistema sanitário italiano da época(4).

No Brasil, o primeiro trabalho sobre o tema teve a autoria de Dirceu dos Reis em sua tese de doutorado pela Faculdade de Odontologia da USP, em 1972, sob a orientação de José Cretella Júnior. Já naquela época, concluiu Dirceu que:

O Direito Sanitário tem autonomia dentro da unidade geral do Direito, porquanto se rege por princípios próprios, possui institutos, métodos, objeto e conceito também próprios. ${ }^{(5)}$

(1) JORIO, Ettore. Diritto sanitario. Milano: Giuffrè, 2005. p. 1.

(2) Sueli Gandolfi Dallari; Arthur Bragança de Vasconcellos Weintraub; Juliano Sarmento Barra; Fernando Mussa Abujamra Aith, entre outros.

(3) Maria Helena Diniz; José Afonso da Silva, entre outros.

(4) LESSONA, Silvio. Trattato di diritto sanitário. Milano: Fratelli Bocca, 1914. v. 1.

(5) REIS, Dirceu dos. Autonomia do direito sanitário. 1972. Tese (Doutorado) - Faculdade de Odontologia, Universidade de São Paulo, São Paulo, 1972. p. 159. 
Também contribuindo para o estudo da autonomia deste ramo do direito e também em tese de doutorado, Fernando Mussa Abujamra Aith escreveu, há pouco tempo, sobre a teoria geral do Direito Sanitário brasileiro, em valorosa contribuição à sistematização dos principais elementos que o compõem e que orientam o regime jurídico deste novo ramo, afirmando que:

O Direito Sanitário representa, dentro desse contexto jurídico, o conjunto de princípios e regras que, transformados em normas jurídicas, regulam a promoção, proteção e recuperação da saúde dos indivíduos e da saúde pública ${ }^{(6)}$.

Verificamos que são poucas as vezes em que os cientistas dedicaramse ao estudo do sistema jurídico sanitário; talvez, porque a luta pela autonomia científica tenha pouca conseqüência prática. No entanto, acreditamos que é de extrema importância científica e didática o reconhecimento da autonomia, considerando que somente dessa maneira teremos o estudo diferenciado dos institutos relacionados a esta matéria e o enquadramento desta na Ciência Jurídica.

Importantes juristas $^{(7)}$ discordam da autonomia do Direito Sanitário, o que nos impõe uma análise profunda se este ramo realmente tem esta característica. Vejamos que a própria professora Sueli Gandolfi Dallari, entendeu não ser ele autônomo. Porém, após revisão de seu entendimento, ensina que:

... já se verificou, também, que dada a complexidade do conceito de saúde, o estudo do direito sanitário envolve - necessariamente - seu exame sob várias óticas. É, então, a partir dessas exigências contemporâneas que se deve discutir a eventual autonomia do direito sanitário como ramo do conhecimento. ${ }^{(8)}$

Neste ponto, sendo o Direito Sanitário um ramo autônomo, tem a liberdade para a identificação de princípios específicos que, na hipótese da nãoautonomia, não teria ${ }^{(9)}$.

(6) AITH, Fernando Mussa Abujamra. Teoria geral do direito sanitário brasileiro. 2006. Tese (Doutorado) - Faculdade de Saúde Pública, Universidade de São Paulo, São Paulo, 2006. p. 103.

(7) Dentre eles, professora Sueli Gandolfi Dallari, que afirmou, em artigo publicado em 1988, que o direito da saúde pública assenta perfeitamente o rótulo de direito administrativo (Uma nova disciplina: o direito sanitário. Revista de Saúde Pública, São Paulo, v. 22, n. 4, p. 327-334, ago. 1988). No entanto, em texto publicado na obra destinada à formação de Membros do Ministério Público e da Magistratura Federal em Direito Sanitário, reviu esta posição afirmando ser o Direito Sanitário um ramo autônomo do Direito. (ARANHA, Márcio lorio (Org.) Direito sanitário e saúde pública. Brasília: Ministério da Saúde, 2003. v. 1, p. 51-55)

(8) ARANHA, Márcio lorio (Org.), op. cit., p. 54.

(9) Como ensina Ruy Barbosa Nogueira (Curso de direito tributário. 14. ed. São Paulo: Saraiva, 1995. p. 33), a separação por motivo puramente didático não pode ser considerada verdadeira autonomia, porque ela não é feita em razão de princípios específicos. 
A dependência com outra Ciência Jurídica só é real caso os princípios são idênticos. Quando isto não ocorre, a autonomia é inerente da ciência fazendo com que o estudo da matéria autônoma caminhe na identificação de suas particularidades, de seus institutos e princípios específicos.

Assim leciona o professor Ruy Barbosa Nogueira:

... toda vez que uma parte do Direito passa a ser estudada autonomamente, por necessidade científica, por diferenciação de princípios, é que podemos realmente falar de um ramo novo, porque existe uma matéria a ser estudada por métodos próprios, constituindo então um sistema de normas jurídicas regidas por princípios diferentes dos princípios que regulam outros ramos jurídicos ${ }^{(10)}$.

Entretanto, muitos declinam a aceitação da autonomia confundindo esta qualidade com o relacionamento científico entre os ramos, resultante da interdisciplinaridade.

Hoje, não podemos aplicar institutos jurídicos de um ramo do Direito sem levar em consideração outros, sejam eles jurídicos, ou não. Talvez, a forma de interpretação sistemática confunda um pouco a identificação da autonomia. Porém, com o aprofundamento no estudo das particularidades da ciência, facilmente é identificada esta qualidade.

O mesmo ocorreu quando da identificação do Direito Tributário, do Direito Previdenciário, do Direito Processual e do Direito do Trabalho que se desprenderam do Direito Administrativo, os dois primeiros, e do Civil, os dois últimos.

Como veremos a seguir, novamente o Direito subdivide-se em mais um ramo autônomo: o Direito Sanitário.

\section{A IMPORTÂNCIA CIENTÍFICA DA DISTINÇÃO DOS RAMOS AUTÔNOMOS E DOS NÃO-AUTÔNOMOS}

A autonomia é uma luta de um ramo dentro da ciência para trilhar seu próprio caminho em busca do aperfeiçoamento contínuo de seus princípios, sem qualquer dependência de alterações significativas de um outro ramo.

Para melhor entender, é necessário estabelecer algumas comparações dos ramos da Ciência Jurídica que recentemente tiveram a mesma mutação, desmembrando-se do ramo de origem. Como o Direito Sanitário nasceu a partir do Direito Administrativo, seguiremos com o estudo da autonomia do Direito Financeiro e Tributário, que teve a mesma origem.

(10) NOGUEIRA. Ruy Barbosa, op. cit., p. 34. 
Discorrendo sobre a autonomia do Direito Financeiro (e Tributário), Aliomar de Andrade Baleeiro explica que as relações jurídicas específicas que decorrem da tributação e da despesa, a índole específica do orçamento $e$ até as peculiaridades dos contratos de empréstimos, quando o devedor é o Estado, definem claramente a autonomia do Direito Financeiro(11). No entanto, nem sempre foi assim, pois, como explica o mesmo professor, alguns escritores, como Griziotti, reputam indesejável a separação dos aspectos jurídicos, políticos e econômicos dos fenômenos fiscais ${ }^{(12)}$.

Completando o pensamento sobre a defesa da autonomia frente aos ramos privados da Ciência Jurídica, alerta Baleeiro que em relação ao ramo da Ciência Jurídica pública, mais exatamente quanto à doutrina do Direito Administrativo, as obras científicas deste reservam reduzidíssimo espaço e quase nenhuma preocupação àquela atividade financeira, deixando transparecer que a sentiam estranhas à cogitações, a despeito da enorme importância de que se reveste ${ }^{(13)}$.

É assim também em relação ao Direito Sanitário. Como afirmamos desde o início, até hoje não há profundos conhecimentos sobre os princípios que regem esta ciência que se mostra, sem dúvida alguma, de grande valia para o desenvolvimento da sociedade. Falta ainda a unidade doutrinária, tendo em vista que fragmentos do ramo jurídico sanitarista percorrem outros como, por exemplo, a saúde do trabalhador dentro do Direito Previdenciário e do Direito Trabalhista. Isto porque o Poder Constitucional Originário previu no capítulo dos direitos sociais trabalhistas a saúde do trabalhador. Porém, apesar desta localização encontrar-se adequadamente empregada, o conceito genérico da saúde, como um direito essencialmente sanitário, possui princípios específicos que norteiam a sua aplicabilidade, não fazendo estes parte do Direito Trabalhista, mas, sim, do Sanitário.

Portanto, com o Direito Sanitário ocorre o mesmo que aconteceu com o Tributário, ou seja, os defensores desta autonomia, bem cedo perceberam que as dificuldades não se reduziam às tendências absorventes dos outros ramos da Ciência Jurídica(14), sendo necessário o estudo apartado, com a formação de especialistas que elaborassem o sistema hoje conhecido como Sistema Nacional Tributário.

Por tudo isso, é de extrema importância o reconhecimento da autonomia do Direito Sanitário. Passamos agora à identificação dos requisitos que legitimam este Direito a ganhar o status de autônomo dentre os outros ramos.

(11) BALEEIRO, Aliomar de Andrade. Direito tributário brasileiro. 9. ed. Rio de Janeiro: Forense, 1977. p. 3.

(12) Id. Ibid., p. 6.

(13) Id. Ibid., p. 5.

(14) Id. Ibid., p. 8. 


\section{DOS REQUISITOS PARA O RECONHECIMENTO DA AUTONOMIA}

Como visto, o requisito para o reconhecimento de um ramo da ciência verdadeiramente autônomo é ter diferença significativa quanto aos seus princípios, impossíveis de serem analisados pelo prisma de outro ramo da Ciência Jurídica.

No Direito Sanitário, a análise de seus princípios específicos ainda não foi abordada pelos cientistas jurídicos da área. Isto porque talvez a Constituição da República não tenha utilizado denominações claras ao observar o que seriam os princípios do Direito Sanitário, qualificando-os, em algumas vezes, como diretrizes. Tomando por exemplo, quando a Constituição diz em seu art. 198, que as ações e serviços públicos de saúde integram uma rede regionalizada e hierarquizada e constituem um sistema único, organizado de acordo com as diretrizes constantes nos incisos especificados, a denominação "diretrizes" não é a mais correta, pois entendemos que nos incisos encontramos verdadeiros princípios do Direito Sanitário.

Neste aspecto, o Direito Ambiental saiu na frente dentre aqueles chamados de direitos sociais desta geração e hoje temos, tanto na doutrina nacional como na internacional, um amplo estudo doutrinário identificando e descrevendo todos os seus princípios e seus institutos.

Além disso, há grande dificuldade no estudo do Direito Sanitário pelos equívocos gramaticais constantes da Constituição da República e da legislação infraconstitucional. Vejamos o art. $7^{\circ}$, da Lei n. 8.080/90, onde não encontramos a ampliação dos princípios constitucionais estabelecidos em seu art. 198. Entendemos serem aqueles denominados "princípios" apenas diretrizes legais, o que demonstra o texto trocado entre a Constituição da República e a Lei Orgânica da Saúde.

Superadas estas dificuldades e com o estudo de todo o sistema jurídico sanitário, podemos identificar, em uma primeira análise, que esta ciência submete-se aos seguintes princípios encontrados na ordem constitucional: princípio da competência concorrente; princípio da unicidade; princípio da participação da sociedade; princípio da universalidade; princípio da prevenção; princípio do risco e do benefício; e princípio da subsidiariedade.

Neste trabalho não caberá a exaustão do estudo de cada princípio do Direito Sanitário, apontados aqui pela primeira vez. Optou-se, assim, por uma concisa explanação do significado de cada um deles para caracterizar e especificar a sua localização dentro deste ramo com o propósito da identificação da autonomia científica, importância transcendental para seu estudo. 


\section{O princípio da competência concorrente}

O princípio da competência concorrente é encontrado no art. 23, inciso II, art. 24, inciso XII, art. 30, incisos I, II e VII, e no art. 198, inciso I, da Constituição da República, sob o nome de descentralização. Entendemos que apenas esta denominação não exponha bem a organização instituída pela legislação sanitária e pela Constituição para a implementação do Sistema Sanitário. Como leciona Maria Sylvia Zanela di Pietro, a descentralização administrativa ocorre quando as atribuições que os entes descentralizados exercem só têm valor jurídico que lhes empresta o ente central; as suas atribuições não decorrem, com força própria, da Constituição, mas do poder centra/(15). Já a descentralização política mencionada no inciso IX, do art. 7으, da Lei n. 8.080/90, ocorre quando o ente descentralizado exercer atribuições próprias que não decorrem do ente central; é a situação dos Estados-membros da federação e, no Brasil, também dos Municípios ${ }^{(16)}$. Celso Antônio Bandeira de Mello acrescenta que a atividade administrativa é descentralizada quando é exercida, em uma das formas mencionadas, por pessoa ou pessoas distintas do Estado(17).

O que ocorre de fato é uma repartição de competência ou, melhor dizendo, um compartilhamento organizado entre as competências administrativas e legislativas ${ }^{(18)}$. Não é propriamente uma descentralização entre os entes federativos com a entrega de poderes administrativos e legislativos entre eles. Assim é a inteligência do art. 24 e de seus parágrafos ${ }^{(19)}$. O compartilhamento organizado confere aos entes federativos e à União o dever de disciplinar sobre a matéria e atuar na aplicação dela, indiferentemente se a lei é federal e o administrador é o município ou vice-versa.

Apenas por meio desta concorrência constitucional de competência, é que se justificaria a atual construção do Sistema Nacional de Saúde, nos moldes do art. 196 da Constituição. Para aclarar esta assertiva, é necessária a transcrição literal da explicação feita pela professora Sueli Gandolfi Dallari que pondera que:

(15) DI PIETRO, Maria Sylvia Zanella. Direito administrativo. 10. ed. São Paulo: Atlas, 1999. p. 296. (16) Id. Ibid.

(17) MELLO, Celso Antônio Bandeira de. Curso de direito administrativo. 17. ed. São Paulo: Malheiros Ed., 2004. p. 139.

(18) DALLARI, Sueli Gandolfi. Os Estados brasileiros e o direito à saúde. São Paulo: Hucitec, 1995. p. 40.

(19) O STF pronunciou-se a respeito do tema afirmando que: "A lei em comento foi editada no exercício da competência supletiva conferida no parágrafo único do art. 8으 da CF/69 para os Estados legislarem sobre a proteção à saúde. Atribuição que permanece dividida entre Estados, Distrito Federal e a União (art. 24, XII da CF/88). Os produtos em tela, além de potencialmente prejudiciais à saúde humana, podem causar lesão ao meio ambiente. O Estado do Rio Grande do Sul, portanto, ao fiscalizar a sua comercialização, também desempenha competência outorgada nos arts. 23, VI e 24, VI da Constituição atual." (RE n. 286.789, Rel. Min. Ellen Gracie, DJ 8.4.05). 
... conforme o disposto na nova ordem constitucional instaurada no Brasil em 1988, a proteção, a defesa e o cuidado da saúde estão sob a responsabilidade das três esferas de governo, cujas ações e serviços devem constituir um sistema que apresente apenas uma direção em cada uma dessas esferas ${ }^{(20)}$.

Por meio deste princípio, a União, o Estado (e Distrito Federal) ou o Município, dependendo do grau de complexidade deste último(21), podem executar serviços sanitários de controle ou de assistência conjuntamente ${ }^{(22)}$ e de forma organizada. Neste sentido, é a redação dos arts. $1^{\circ}, 4^{\circ}$ e $7^{\circ}$, incisos IX, XI, XII e XIII, da Lei n. 8.080/90.

Os entes federativos têm também, consoante expõem os arts. 24, inciso XII e 30, inciso I, ambos da Constituição da República, competência concorrente para legislar sobre o assunto, nos termos das regras constitucionais.

A hierarquia não é real, mas, sim, subsidiária, já que todos os entes públicos têm o dever da prestação de serviços à saúde, conforme o art. 196 da Constituição da República e também do art. 1ํ, da Lei n. 8.080/90, que determina: esta lei regula, em todo o território nacional, as ações e serviços de saúde, executados isolada ou conjuntamente, em caráter permanente ou eventual, por pessoas naturais ou jurídicas de direito público ou privado. E existe uma organização que obedece à repartição legal e constitucional de competência e, na falta de um ente específico, o que possuir maior competência técnica deverá supri-lo obrigatoriamente. É a chamada competência concorrente não-cumulativa ou vertical(23). Não existe imposição entre os entes e sim uma forma compartilhada e organizada para a busca de um só fim — a saúde pública.

Embora este sistema se comporte com um planejador centralizado representado pela União, as interações do sistema federativo repartilhado conduzem a um equilíbrio melhor, ainda que não necessariamente o ótimo projetado, e aí temos a idéia da eqüidade em saúde.

A forma de suprir estes serviços públicos pelo princípio da competência concorrente significa que todos os envolvidos no Sistema - sejam eles pessoas de direito público ou privado - têm o dever constitucional de executar o serviço dentro da forma institucionalizada e organizada prevista nas leis de organização do Sistema Único de Saúde e na legislação esparsa.

O Capítulo IV, Seção I, da Lei n. 8.080/90 define que a União, os Estados, o Distrito Federal e os Municípios exercerão, em seu âmbito administrativo,

(20) DALLARI, Sueli Gandolfi, op. cit., p. 79.

(21) Art. 7º, inciso IX, alínea a, da Lei n. 8.080/90 e art. 30, inciso VII, da Constituição.

(22) É neste sentido a redação do art. 194 da Constituição que conceitua a seguridade social como um conjunto integrado de ações de iniciativa dos Poderes Públicos e da sociedade, destinadas a assegurar os direitos relativos à saúde.

(23) Art. 24, § 2º da Constituição da República. 
competência comum para a execução das atividades relacionadas à saúde. Se formos analisar os arts. 16, 17 e 18, da Lei Orgânica da Saúde (8.080/90), que trata das competências da União, Estados e Municípios, respectivamente, a essência dos serviços é repetida a todos os entes federativos.

Assim, a competência é repartida entre os entes federativos e a iniciativa privada devidamente autorizada, dentro do Sistema; mas, todos compartilham de forma subsidiária, do menor ente federativo para o maior, a obrigação imposta pelo art. 196 da Constituição da República, como bem ressaltado por Sueli Gandolfi Dallari ${ }^{(24)}$. Encontramos, assim, o princípio da unicidade.

\section{O princípio da unicidade}

Segundo o princípio da unicidade, o serviço é único e deve ser executado por alguém, seja ele da iniciativa privada, mediante autorização de serviços quando cabível, seja qualquer um dos entes federativos. O não cumprimento da prestação do serviço pode acarretar até mesmo a omissão de socorro para quem deixar de executar serviços de urgências.

O princípio da unicidade imprime ao Sistema Nacional Sanitário uma auto-organização necessária para a consecução de seu fim. A unicidade também decorre de um conceito geral de que o Sistema de Saúde brasileiro possui a peculiaridade de ser auto-resolutível ${ }^{(25)}$. Hoje, não existe outro modo de proteção à saúde sem que seja sob o manto do Sistema Único da Saúde.

\section{O princípio da participação da sociedade}

A Constituição da República prevê, juntamente com a Lei n. 8.080/ 90, a participação da sociedade, por intermédio de conselhos e outros organismos, com a finalidade de instituição das diretrizes específicas para a destinação de recursos econômicos e implementação de políticas públicas, no sentido de articular programas de interesse à saúde nas áreas de alimentação e nutrição, saneamento e meio ambiente, vigilância sanitária e farmacoepidemiologia, recursos humanos, ciência e tecnologia e saúde do trabalhador ${ }^{(26)}$, ou por meio da participação da iniciativa privada na produção de bens de consumo e de serviços à saúde. Este é o princípio da participação da sociedade.

(24) DALLARI, Sueli Gandolfi. op. cit.

(25) Tal consideração, levou Germano Schwartz ( $O$ tratamento jurídico do risco no direito à saúde. Porto Alegre: Livr. do Advogado, 2004. p. 57) a afirmar que: "pode-se dizer que o sistema sanitário atingiu um grau tal de funcionalidade que se tornou autônomo."

(26) Cf. arts. 12 e 13 da Lei n. 8.080/90. 
A participação da sociedade no sistema sanitário é prevista desde $1937^{(27)}$. Porém, somente após a promulgação da Constituição de $1988^{(28)}$, e com as diretrizes da Lei n. 8.080/90, tivemos efetivamente a participação destes Conselhos na política de saúde nacional. Hoje, por esta razão, existem tanto o Conselho Nacional de Saúde, como os Conselhos Estaduais, Distrital e Municipais de Saúde.

Este direito de participação popular na construção da política da saúde foi um avanço da sociedade, a partir de um movimento que conseguiu junto à Constituinte implementar um sistema de participação social só encontrado no Sistema Constitucional Sanitário.

Como explica Adalgiza Balsemão, no início dos anos 80, o Movimento Sanitário já contava com o apoio e o reconhecimento do movimento popular, sindical e de setores da sociedade que buscavam os direitos sociais ${ }^{(29)}$.

A Constituição prevê, também, a participação da iniciativa privada, por meio do art. 199, que institui regras para a livre iniciativa privada na assistência à saúde e na produção de bens e serviços. No entanto, mais adiante, exatamente no art. 200, incisos I, VI e VII, estão estabelecidas as condições para a execução de serviços e a produção de produtos destinados à saúde.

Com isso, percebe-se que a palavra final na realização da maioria das políticas econômicas e sociais, das quais trata o art. 196 da Constituição da República e que delimita o princípio da universalidade, é da sociedade.

\section{O princípio da universalidade}

De acordo com a Constituição da República, a saúde é um direito de acesso universal(30). Deste direito constitucional, extraímos o princípio da universalidade que corresponde à efetiva distribuição dos serviços e produtos para a garantia da saúde pública, com livre acesso para todos ${ }^{(31)}$, independentemente de qualquer tipo de condição(32), exceto pela limitação financeira ${ }^{(33)}$

(27) Instituída pela Lei n. 378, de 13 de janeiro de 1937, não considerava a necessidade de participação dos municípios, nem dos usuários e trabalhadores do setor.

(28) A participação da sociedade está prevista no art. 198, inciso III, da Constituição da República.

(29) ARANHA, Márcio lorio (Org.), op. cit., p. 290.

(30) Art. 198, inciso I, primeira parte: As ações e serviços públicos de saúde integram uma rede regionalizada e hierarquizada e constituem um sistema único, organizado de acordo com as seguintes diretrizes: II - atendimento integral; (...).

(31) $\mathrm{O}$ art. $2^{\circ}$ da Lei n. 8.080/90, explica que: a saúde é um direito fundamental do ser humano, devendo o Estado prover as condições indispensáveis ao seu pleno exercício. O pleno exercício é a essência do princípio da universalidade.

(32) Este entendimento deve respeitar o princípio constitucional da justiça social (SILVA, José Afonso da. Curso de direito constitucional positivo. 5. ed. São Paulo: Ed. Revista dos Tribunais, 1989. p. 108), referido no art. 170, que apregoa a realização da democracia social e cultural.

(33) Um aspecto muito importante é que a limitação financeira aqui presente não pode prejudicar a sociedade enquanto receptora dos serviços e dos produtos para a saúde, como imposição do princípio da eficiência administrativa, ou seja, a transferência financeira não pode ser limitada ao ponto que haja uma verdadeira falência do Sistema de Saúde Pública brasileira. 
que o Estado tem, definida por seu sistema de arrecadação e pelas decisões tomadas pelos Conselhos de Saúde (Nacional, Estaduais, Distrital e Municipais), com fundamento no art. 198, $\S \S 1 ํ$ e $2^{\circ}$ da Constituição.

Este sistema possui uma rede de financiamento organizado por lei e com previsão orçamentária anual de fim social. Neste sentido, o texto do art. 31 da Lei Orgânica da Saúde que prevê receita estimada, para a consecução dos recursos necessários à realização de suas finalidades, previstos em proposta elaborada pela sua direção nacional, com a participação dos órgãos da Previdência Social e da Assistência Social, tendo em vista as metas e prioridades estabelecidas na Lei de Diretrizes Orçamentárias.

Deve-se deixar bem claro que esta é a única condição existente para o fornecimento deste bem jurídico à sociedade. Qualquer outra limitação é inconstitucional e ilegal, diante do sistema constitucional de proteção ao direito à saúde.

Este princípio está diretamente ligado também à extensão da cobertura do Sistema Nacional de Vigilância Sanitária e Epidemiológica sendo que, pela universalização do direito à saúde, é imposto ao Estado que atue com a fiscalização, com o objetivo de reduzir o risco de doença e de outros agravos.

\section{O princípio da prevenção}

Passamos agora para um dos princípios fundamentais do Direito Sanitário: o princípio da prevenção, segundo o qual o Estado deve antever as situações de fato para que não haja a deterioração da saúde diante de seus tutelados $^{(34)}$. Este princípio, base para os direitos sociais, está diretamente relacionado à impossibilidade de reconstituição do direito ${ }^{(35)}$. Isto significa que, enquanto no Direito Civil a regra geral é descrever as circunstâncias e as conseqüências de direito delas advindas, como também no Direito do Trabalho, que estipula as situações entre empregados e empregadores ou, até mesmo, no Direito Previdenciário, que define as condições para a formação de direitos futuros, no Direito Sanitário, raramente são descritas as conseqüências das circunstâncias as quais o direito irá tutelar, importando-se, de regra, a fixação de atos fiscalizatórios, repressivos e, até mesmo, com a atuação do poder de polícia do Estado para evitar a ocorrência do fato danoso à saúde ${ }^{(36)}$.

(34) Este é o objetivo do Sistema Único da Saúde (SUS), por meio da assistência às pessoas por intermédio de ações de promoção, proteção e recuperação da saúde, com a realização integrada das ações assistenciais e das atividades preventivas (art. 5oㅡㄹ inciso III, da Lei n. 8.080/90).

(35) RODRIGUES, Marcelo Abelha. Instituição de direito ambiental. São Paulo: Max Limonad, 2002. v. 1, p. 148.

(36) AITH, Fernando Mussa Abujamra, op. cit., p. 337. 
Leciona José Afonso da Silva que os direitos sociais, como dimensão dos direitos fundamentais do homem, são prestações positivas estatais, enunciadas em normas constitucionais, que possibilitam melhores condições de vida aos mais fracos, direitos que tendem a realizar a igualização de situações sociais desiguais ${ }^{(37)}$. Estas prestações positivas atendem o que denominamos princípio da prevenção.

Exemplificando: se o Estado não proporcionar a prevenção à saúde mediante políticas de segurança do trabalho ${ }^{(38)}$, as conseqüências dessa falta da atuação que implica diretamente no princípio da prevenção, afetarão a percepção do direito ao auxílio-doença acidentário, instituto do Direito Previdenciário. A falta de prevenção à saúde pode influenciar ainda direitos civis, trabalhistas, penais etc.

O princípio da prevenção é, assim, o mais importante instrumento do Estado para concessão do direito à saúde, nos moldes do art. 196 da Constituição, para os seus súditos, e com previsão textual no art. 198, inciso II, que dá prioridade para as atividades preventivas.

\section{O princípio do risco e do benefício}

Para coadjuvar com este princípio, extraímos da Constituição o princípio do risco e do benefício, o qual exige que o Estado saiba dosar os riscos para a realização da atividade de fiscalização sanitária, sem que haja a redução de benefícios à sociedade. Assim, se um medicamento faz muito mal à saúde, mas é necessário para manter a vida de um paciente, mesmo que a droga venha a causar malefícios ao mesmo, porém, com mais chances de sobrevida, o Estado deve optar pelo registro do produto. Sem este princípio, verificando-se que o produto é simplesmente maléfico à saúde, o Estado não poderia registrá-lo.

Portanto, por meio do princípio do risco e do benefício, considerando os produtos e os serviços que apresentem riscos à saúde humana, sejam estes biológicos ou qualquer outro de relevância sanitária ${ }^{(39)}$, devem ser eles controlados pelo Estado-regulador e fiscalizador.

O mesmo ocorre quando o Estado, através do Poder Judiciário, recebe um pedido de fornecimento de medicamento excepcional que não é comportado pelo Sistema Único de Saúde. O Estado, por meio do Juiz, deverá negar o direito ao acesso a este medicamento, pois o risco de muitos em não

(37) SILVA, José Afonso da, op. cit., p. 253.

(38) Art. 200, incisos II e VIII, última parte, da Constituição.

(39) São várias as hipóteses que ensejam a identificação do risco sanitário, dentre elas o risco biológico, do trabalho, ambiental etc. 
receber o medicamento regular pela falta de condições de financiamento que será destinado para aquisição deste medicamento excepcional, sempre de maior valor tendo em vista a sua excepcionalidade, sobrepõe-se ao direito de uma só pessoa. Parece cruel, mas é preciso lembrar que a distribuição deve respeitar os limites e a regra do risco $x$ benefício, presente no Direito Sanitário ${ }^{(40)}$.

Assim, explica Celso Ribeiro Bastos que a atividade pública não consegue satisfazer a todas as necessidades coletivas. Essa a razão da inevitabilidade da intermediação de uma escolha feita pelos governantes, que optam dentre as necessidades coletivas por aquelas que merecem satisfação por meio de uma atividade pública. As necessidades assim satisfeitas recebem a qualificação de necessidades públicas ${ }^{(41)}$.

Impõe este princípio a aplicação incondicional de um outro princípio administrativo: o da supremacia do interesse público. Como explica Maria Sylvia Zanella di Pietro, o direito deixou de ser apenas instrumento de garantia dos direitos do indivíduo e passou a ser visto como meio para consecução da justiça social, do bem comum, do bem-estar coletivo(42).

A este princípio, existem subprincípios como o princípio da precaução, princípio da equivalência e princípio da acreditação que se unem para instrumentalizar a redução dos riscos com a supremacia dos benefícios.

\section{O princípio da subsidiariedade}

O princípio da subsidiariedade surgiu quando o Estado percebeu que não conseguiria prestar os serviços de saúde e produzir produtos sem a participação ativa da iniciativa privada, ficando ele responsável pela saúde daqueles que optassem pela assistência privada à saúde. Ainda hoje, o Sistema necessita deste coadjuvante, que atualmente é o ator principal num sistema criado para o atendimento a todos, conforme já enunciado no princípio universalidade. Os arts. 199, § $1^{\circ}$ e 200 da Constituição da República são bem claros em observar a necessidade desta complementação, sendo que condicionam estas atividades à regulação por órgãos específicos, os quais foram a base para a criação dos órgãos de fiscalização sanitária e deram início às Agências Reguladoras.

(40) Assim, já se decidiu nos Tribunais que: Definidas pela Administração as metas prioritárias na área de saúde pública, dentro do âmbito da discricionariedade de que dispõe e sem ofensa aos limites legais e constitucionais, não cabe ao Judiciário perquirir os critérios adotados, tampouco substituílos. Daí porque, na espécie, não padece de ilegalidade a Portaria n. 763 , de 7.4.94, editada pelo Ministério da Saúde, que proibiu o custeio de tratamento médico no exterior por conta do Estado. (TRF1 — AMS n. 200034000427601-DF — Primeira Turma — Des. José Amílcar Machado, DJ 7.7.03). (41) BASTOS, Celso Ribeiro. Curso de direito financeiro e de direito tributário. 3. ed. São Paulo: Saraiva, 1995. p. 4.

(42) DI PIETRO, Maria Sylvia Zanella, op. cit., p. 62. 
Entendendo o sistema sanitário como sendo predominantemente uma atividade do Estado de implementação de políticas públicas, financiamento público da saúde e execução das atividades preventivas, a subsidiariedade, aqui entendida dentro da atividade privada, ganha relevo para reduzir o comprometimento da Administração nesta atividade direta, abrindo a possibilidade também para que novas figuras de organizações sociais prestem estes serviços dentro dos novos modelos de parcerias público-privadas, ficando o Estado, privativamente, com o controle e a organização das atividades de saúde.

Como define José Alfredo de Oliveira Baracho, a subsidiariedade aqui deve ser entendida como sendo uma forma de desempatar concorrentes, ou seja, se existe uma operadora que deve estruturar o atendimento da assistência à saúde de seus usuários, ela terá a preferência e somente na falência de sua atividade, o Estado irá subsidiar seu dever ${ }^{(43)}$.

\section{Demais princípios}

Afora estes princípios específicos, não podemos esquecer que como o Direito Sanitário é um Direito Público, ele deve obedecer aos princípios constitucionais de atuação estatal previstos nos arts. 5o e 37, caput, da Constituição da República, quais sejam: princípio da legalidade; princípio da supremacia do interesse público; princípio da impessoalidade; princípio da publicidade; princípio da eficiência e princípio da moralidade, além dos princípios administrativos verificados pela doutrina mediante a interpretação da legislação como o princípio da razoabilidade, da autotutela ${ }^{(44)}$, da finalidade e da segurança jurídica ${ }^{(45)}$.

\section{A AUTONOMIA DO DIREITO SANITÁRIO}

Os princípios ora comentados fundamentam a assertiva de que o Direito Sanitário é um ramo autônomo e interdisciplinar da Ciência Jurídica. Autônomo porque possui princípios e institutos próprios e interdisciplinar porque se completa com os princípios gerais de outras ciências.

(43) BARACHO, José Alfredo de Oliveira. O princípio de subsidiariedade. Rio de Janeiro: Forense, 2000. p. 24.

(44) Estes dois princípios, o da razoabilidade e o da autotutela, são abordados por Maria Sylvia Zanella di Pietro (Direito administrativo, cit., p. 72 e 65-66, respectivamente), sendo o primeiro decorrente do princípio da legalidade investida de seus atos e o segundo, previsão constitucional paulista com o intuito de limitar a atuação da imposição de atos discricionários aos seus tutelados. (45) Quanto aos últimos princípios, previstos no Curso de Direito Administrativo, de autoria do professor Celso Antônio Bandeira de Mello (Curso de direito administrativo, cit., p. 97-99 e 112-115, respectivamente), a razoabilidade influi nos fundamentos dos atos discricionários e, quanto ao segundo, impõe a estabilidade das relações e da intenção administrativa sem que hajam mutações significativas que alterem uma segurança inerente das atividades humanas. 
A geração de novos direitos, acentuada durante os séculos $\mathrm{XIX}$ e $\mathrm{XX}$, deu impulso à formação de ramos jurídicos verdadeiramente autônomos que se desenvolveram para acompanhar a evolução científica da Revolução Industrial, primeiramente, e, depois, com a Revolução Social surgida na última metade do século $X X$, instituindo na Ciência Jurídica, a finalidade da proteção de direitos coletivos e sociais até então não concebidos pelo Direito.

O direito à saúde foi consolidado por meio da nossa Constituição de 1988. Ele está localizado na nossa Carta Magna entre os direitos sociais, previsto desde o preâmbulo sob nome de "bem-estar". A saúde tornou-se um dos mais importantes direitos do homem, concebido por meio de lutas contra um sistema que não provia o bem-estar da sociedade, estando ao lado dos então novos direitos, como o direito à proteção do meio ambiente, dos consumidores, das relações de trabalho, entre outros.

Verificando a importância deste direito social, o constituinte proporcionou uma seção inteira na Constituição para tratar do assunto. Especificou, ainda, princípios sob o nome de "diretrizes" e repetiu nada menos que oito vezes $^{(46)}$ a importância da garantia deste dever para o Estado e deste direito para seus tutelados.

As circunstâncias aqui levantadas preenchem os requisitos expostos por Alfredo Rocco, para caracterizar a autonomia de um ramo científico. Segundo este autor, uma ciência é autônoma quando: seja ela vasta a ponto de merecer um estudo de conjunto, adequado e particular; ela contenha doutrinas homogêneas dominadas por conceitos gerais comuns e distintos dos conceitos gerais que informam outras disciplinas e possua método próprio, empregando processos especiais para o conhecimento das verdades que constituem objeto de suas investigações ${ }^{(47)}$.

É, assim, o Direito Sanitário, um ramo verdadeiramente autônomo da Ciência Jurídica em toda a sua concepção.

\section{AUTONOMIA E INTERDISCIPLINARIDADE}

A autonomia do Direito Sanitário não significa que ele não seja interdisciplinar. A interdisciplinaridade é uma condição inerente das Ciências Jurídicas na atualidade. Assim, por exemplo, o Direito Administrativo depende do Direito Civil e do Direito Comercial para a aplicação das regras às empresas públicas e para a regulação da responsabilidade do Estado perante o particular. Não podemos esquecer do Direito Constitucional, base

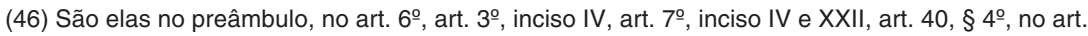
194 e no art. 196 da Constituição da República.

(47) Apud MARTINS, Sergio Pinto. Direito do trabalho. 15. ed. São Paulo: Atlas, 2002. p. 49. 
principal de todas as ciências jurídicas, que influencia na aplicação de todos os demais ramos do Direito. A autonomia compreende a independência do ramo do Direito que possui seus princípios específicos.

A interdisciplinaridade consiste em várias conexões existentes entre os ramos e as ciências para a consecução das regras complexas do Direito. Assim, o Direito Sanitário tem relação mais próxima com o Direito Administrativo e o Direito Constitucional. Em relação ao Administrativo, tendo em vista que é dever do Estado manter o direito à saúde e que sua atuação se dá por meio da função administrativa exaurida pelos diversos órgãos do Sistema ${ }^{(48)}$, a administração pública instituiu órgãos, pessoas jurídicas de direito público e pessoas jurídicas e físicas de direito privado, autorizados à execução do serviço.

Já o Direito Constitucional concentra os princípios e as diretrizes gerais de efetivação do direito à saúde.

Tais princípios e institutos administrativos e constitucionais são in genere, como bem lembra José Cretella Júnior, e não cabe a nenhum dos ramos da ciência do direito reivindicar, para seu campo, a prioridade de um dado instituto, quando esse instituto é comum a vários setores do direito ${ }^{(49)}$.

Do mesmo modo que o Direito Civil não pode determinar que seja exclusividade sua a utilização de certos princípios e institutos, o Direito Administrativo e, muito menos o Direito Constitucional, poderá avocar tal desejo.

\section{CONSIDERAÇÕES FINAIS}

Diante de tudo isso, percebemos a importância de constituir no Direito Sanitário um ramo autônomo da Ciência Jurídica, sendo pré-requisito para a evolução da garantia ao direito à saúde e relacionado com os demais ramos que extraem sistemas jurídicos específicos para a tutela dos diversos direitos à saúde.

Apesar de autônomo, o Direito Sanitário está sujeito, como todos os direitos públicos, aos princípios e regras do Direito Administrativo, como bem esclarece Celso Antônio Bandeira de Mello, sendo, assim, um campo recoberto pela função administrativa, constituindo-se em um ramo temático tão sujeito ao regime jurídico administrativo como qualquer outra ciência(50).

(48) MELLO, Celso Antônio Bandeira de, op. cit., p. 35.

(49) CRETELLA JÚNIOR, José. Tratado de direito administrativo. 2. ed. Rio de Janeiro: Forense, 2002, v. 2. p. 20.

(50) MELLO, Celso Antônio Bandeira de, op. cit., p. 36. 
Concluímos, portanto, que o Direito Sanitário é assim um ramo autônomo e interdisciplinar do Direito Público, por excelência, destinado a orientar interesses sociais, individuais e gerais da sociedade(51), voltado a garantir e a controlar a distribuição do bem jurídico da saúde aos cidadãos, tendo regras, princípios constitucionais e diretrizes legais a serem observados nesta função imprescindível da manutenção do Estado Democrático de Direito ${ }^{(52)}$.

\section{REFERÊNCIAS BIBLIOGRÁFICAS}

AITH, Fernando Mussa Abujamra. Teoria geral do direito sanitário brasileiro. 2006. Tese (Doutorado) - Faculdade de Saúde Pública, Universidade de São Paulo, São Paulo, 2006.

ARANHA, Márcio lorio (Org.) Direito sanitário e saúde pública. Brasília: Ministério da Saúde, 2003. v. 1.

BALEEIRO, Aliomar de Andrade. Direito tributário brasileiro. 9. ed. Rio de Janeiro: Forense, 1977.

BARACHO, José Alfredo de Oliveira. O princípio de subsidiariedade. Rio de Janeiro: Forense, 2000.

BASTOS, Celso Ribeiro. Curso de direito financeiro e de direito tributário. 3. ed. São Paulo: Saraiva, 1995.

BELVĖZE, Henri. Le principe de précaution et ses implications juridiques dans le domaine de la sécurité sanitaire des aliments. Revue Scientifique et Technique, Paris, v. 22, n. 2, p. 387-396, 2003.

CRETELLA JÚNIOR, José. Tratado de direito administrativo. 2. ed. Rio de Janeiro: Forense, 2002. v. 2.

DALLARI, Sueli Gandolfi. Uma nova disciplina: o direito sanitário. Revista de Saúde Pública, São Paulo, v. 22, n. 4, p. 327-334, ago. 1988. 1995.

Os Estados brasileiros e o direito à saúde. São Paulo: Hucitec,

1985

Municipalização dos serviços de saúde. São Paulo: Brasiliense,

DI PIETRO, Maria Sylvia Zanella. Direito administrativo. 10. ed. São Paulo: Atlas, 1999.

(51) MONTEIRO, Washington de Barros. Curso de direito civil. 11. ed. São Paulo: Saraiva, 1972. p. 9.

(52) Como afirma José Afonso da Silva (op. cit., p. 106), a Constituição de 1988 abre as perspectivas de realização social profunda pela prática dos direitos sociais que ela inscreve e pelo exercício dos instrumentos que oferece à cidadania e que possibilita concretizar as exigências de um Estado de justiça social, fundado na dignidade da pessoa humana. 
JORIO, Ettore. Diritto sanitário. Milano: Giuffrè, 2005.

LESSONA, Silvio. Trattato di diritto sanitário. Milano: Fratelli Bocca, 1914. v. 1. LACAZ, Francisco Antonio de Castro. Processos produtivos e riscos para a saúde. Revista de Vigilância Sanitária, São Paulo, v. 1, n. 1, 2005.

MARTINS, Sergio Pinto. Direito do trabalho. 15. ed. São Paulo: Atlas, 2002.

MELLO, Celso Antônio Bandeira de. Curso de direito administrativo. 17. ed. São Paulo: Malheiros Ed., 2004.

MONTEIRO, Washington de Barros. Curso de direito civil. 11. ed. São Paulo: Saraiva, 1972.

NOGUEIRA, Ruy Barbosa. Curso de direito tributário. 14. ed. São Paulo: Saraiva, 1995.

REIS, Dirceu dos. Autonomia do direito sanitário. 1972. Tese (Doutorado) Faculdade de Odontologia, Universidade de São Paulo, São Paulo, 1972.

RODRIGUES, Marcelo Abelha. Instituição de direito ambiental. São Paulo: Max Limonad, 2002. v. 1.

SCHWARTZ, Germano. O tratamento jurídico do risco no direito à saúde. Porto Alegre: Livraria do Advogado, 2004.

SILVA, José Afonso da. Curso de direito constitucional positivo. 5. ed. São Paulo: Ed. Revista dos Tribunais, 1989.

ZAPLANA, José Guerrero. Salud pública y derecho administrativo. Cuadernos de derecho judicial. Madrid: Consejo General Del Poder Judicial, 2004. v. 5 . 